\title{
Transareolar single-port endoscopic thoracic sympathectomy with a flexible endoscope for primary palmar hyperhidrosis: a prospective randomized controlled trial
}

\author{
Jian-Bo Lin ${ }^{1,2 \#} \wedge$, Ming-Qiang Kang ${ }^{2 \#}$, Jian-Feng Chen $^{1} \wedge$, Quan $\mathrm{Du}^{1} \wedge$, $\mathrm{Xu} \mathrm{Li}^{1} \wedge$, Fan-Cai Lai ${ }^{1 \wedge}$, \\ Yuan-Rong $\mathrm{Tu}^{1 \wedge}$ \\ ${ }^{1}$ Department of Thoracic Surgery, Palmar Hyperhidrosis Research Institute, First Affiliated Hospital of Fujian Medical University, Fuzhou, China; \\ ${ }^{2}$ Department of Thoracic Surgery, Fujian Medical University Union Hospital, Fuzhou, China \\ Contributions: (I) Conception and design: JF Chen; (II) Administrative support: X Li, MQ Kang; (III) Provision of study materials or patients: YR Tu; \\ (IV) Collection and assembly of data: JB Lin, Q Du; (V) Data analysis and interpretation: FC Lai; (VI) Manuscript writing: All authors; (VII) Final \\ approval of manuscript: All authors. \\ "These authors contributed equally to this work. \\ Correspondence to: Jian-Feng Chen, MD, PhD. Department of Thoracic Surgery, First Affiliated Hospital of Fujian Medical University, 20 Chazhong \\ Road, Fuzhou 350005, China. Email: chenjianfengmd@163.com.
}

Background: Transareolar single-port endoscopic thoracic sympathectomy (ETS) with a flexible endoscope has rarely been reported. This study assessed the performance of this novel minimally invasive technique for primary palmar hyperhidrosis (PPH).

Methods: From January 2019 to September 2019, 118 males with severe PPH requiring single-port and bilateral ETS were randomly allocated to undergo transareolar ETS using a flexible endoscope (group A, $\mathrm{n}=58$ ) or transaxillary ETS using a $5 \mathrm{~mm}$ thoracoscope (group B, $\mathrm{n}=60$ ).

Results: Both groups had similar patient characteristics. All procedures were performed successfully, with no mortality or conversion to open surgery. All patients had dry and warm palms immediately after surgery. Compared with group B, group A had a significantly shorter median incision length [5.1 (5.0-5.2) vs. 10.9 (10.8-11.9) mm; $\mathrm{P}<0.001]$, and significantly lower median postoperative pain score [1 (1.0-2.0) vs. 3 (3.0-4.0); $\mathrm{P}<0.001]$. There were no differences between the two groups in operative time, palmar temperature increase, and transient postoperative sweating. After complete follow-up, group A had a significantly higher median cosmetic score than group B [4.0 (3.0-4.0) vs. 3.0 (3.0-3.0); $\mathrm{P}<0.001]$. There were no differences between the two groups regarding symptom resolution, compensatory hyperhidrosis, and satisfaction score. No patient reported residual pain or symptom recurrence.

Conclusions: Transareolar single-port ETS with a flexible endoscope is safe, effective, and minimally invasive with a small incision, minimal pain, and excellent cosmetic results. This novel procedure is suitable for routine treatment of $\mathrm{PPH}$ in males.

Keywords: Primary palmar hyperhidrosis (PPH); endoscopic thoracic sympathectomy (ETS); areolar approach

Submitted Oct 19, 2020. Accepted for publication Dec 02, 2020.

doi: 10.21037/atm-20-7399

View this article at: http://dx.doi.org/10.21037/atm-20-7399

\footnotetext{
^ ORCID: Jian-Bo Lin, 0000-0002-7484-6143; Ming-Qiang Kang, 0000-0002-8391-3942; Jian-Feng Chen, 0000-0002-1658-8326; Quan Du, 0000-0003-0901-0240; Xu Li, 0000-0002-5551-918X; Fan-Cai Lai, 0000-0002-4343-2212; Yuan-Rong Tu, 0000-0002-7150-7672.
} 


\section{Introduction}

Primary palmar hyperhidrosis ( $\mathrm{PPH})$ is characterized by excessive perspiration with physiologically needed thermoregulation (1). The disease is a form of primary focal hyperhidrosis $(\mathrm{PFH})$, which mainly manifests as hyperhidrosis in many areas of the body, but the most distressing areas are palms, plantar surface and axillae (2), causing severe psychological, social, and occupational dysfunction. The degree of sweating is variable and ranges from moderate moisture to severe dripping (3). The prevalence of $\mathrm{PPH}$ in different populations also varies, and is reportedly 2.08\% in China (4), 2.8\% in the United States (5), and $5.5 \%$ in Brazil (6). Although the cause of PPH remains unknown, a novel locus has recently been identified on chromosome 2q31.1 (7).

Conservative treatment of PPH mainly includes external use of antiperspirants, oral cholinergic receptor blocker, electro-osmotic therapy, local injection of botulinum toxin A and CT-guided percutaneous sympathetic block (8-10), but the effect usually last for a short time, with a high recurrence rate or even invalid (11-13). Currently, endoscopic thoracic sympathectomy (ETS) is one of the most effective and sustainable surgical methods for the treatment of $\mathrm{PPH}$ (14). The surgical procedures have been updated several times over the past few years. For example, the three-port method has been replaced by the one-port method. Transaxillary single-port ETS is a commonly used traditional surgical treatment, which is minimally invasive, cosmetic, and can be applied to both male and female patients. However, the disadvantage is that the carbon dioxide cannot be used to form an artificial pneumothorax, and the operative field is not well exposed. In the previous reported studies $(15,16)$, rigid thoracoscope was used in ETS, both thoracoscope and electrocoagulation hook were inserted in the same incision during the surgical operation, which occasionally caused intrathoracic operation inconvenience and intercostals nerve injury, resulting in postoperative chest pain. As part of the continuing development of endoscopic surgery, a flexible endoscope has recently been designed for the diagnosis and treatment of thoracic diseases (17), wherein the instrumental flexibility allows intrathoracic navigation by minimally invasive approaches. Using a flexible endoscope to perform transareolar ETS enables the incision to be hidden in the areola and may offer better cosmetic results in comparison with traditional ETS. The present study was a randomized controlled trial that compared the results of transareolar single-port ETS using a flexible endoscope (Figures 1,2,3) versus conventional transaxillary single-port ETS using a $5 \mathrm{~mm}$ thoracoscope (Figure 4). We present the following article in accordance with the CONSORT reporting checklist (available at http://dx.doi.org/10.21037/atm-207399).

\section{Methods}

\section{Objectives}

Cosmetic score was obtained by verbal response scale (VRS, Table 1). The cosmetic score was the primary endpoint, and one-sided values of $\mathrm{P}<0.05$ were considered statistically significant. The secondary endpoints were mean incision length, mean postoperative pain score, postoperative analgesia, mean operating time, mean probe temperature increase, intraoperative bleeding, postoperative pneumothorax, chest drainage for pneumothorax, transient postoperative sweating, resolution of symptoms, compensatory hyperhidrosis, and mean satisfaction score. One-sided values of $\mathrm{P}<0.004$ were considered statistically significant.

\section{Patient selection}

From January 2019 to September 2019, 124 male patients with severe PPH (3) were enrolled to randomize for treated with single-port bilateral ETS at our institution. All patients underwent preoperative routine blood examination, cardiological consultation, and chest-computed tomography to exclude lung, pleural, and heart diseases. Moreover, a detailed medical history including severity of symptoms and distribution of excessive sweating was also recorded.

\section{Enrolment and randomization}

The present study was approved by the institutional review board and ethics committee of the First Affiliated Hospital of Fujian Medical University (approval no. 2015-17). All procedures performed in studies involving human participants were in accordance with the ethical standards of the institutional and/or national research committee and with the study conformed to the provisions of the Declaration of Helsinki (as revised in 2013). Prior to randomization, patients were carefully screened for eligibility in accordance with the inclusion and exclusion criteria. The inclusion criteria were as follows: age $\geq 16$ and 

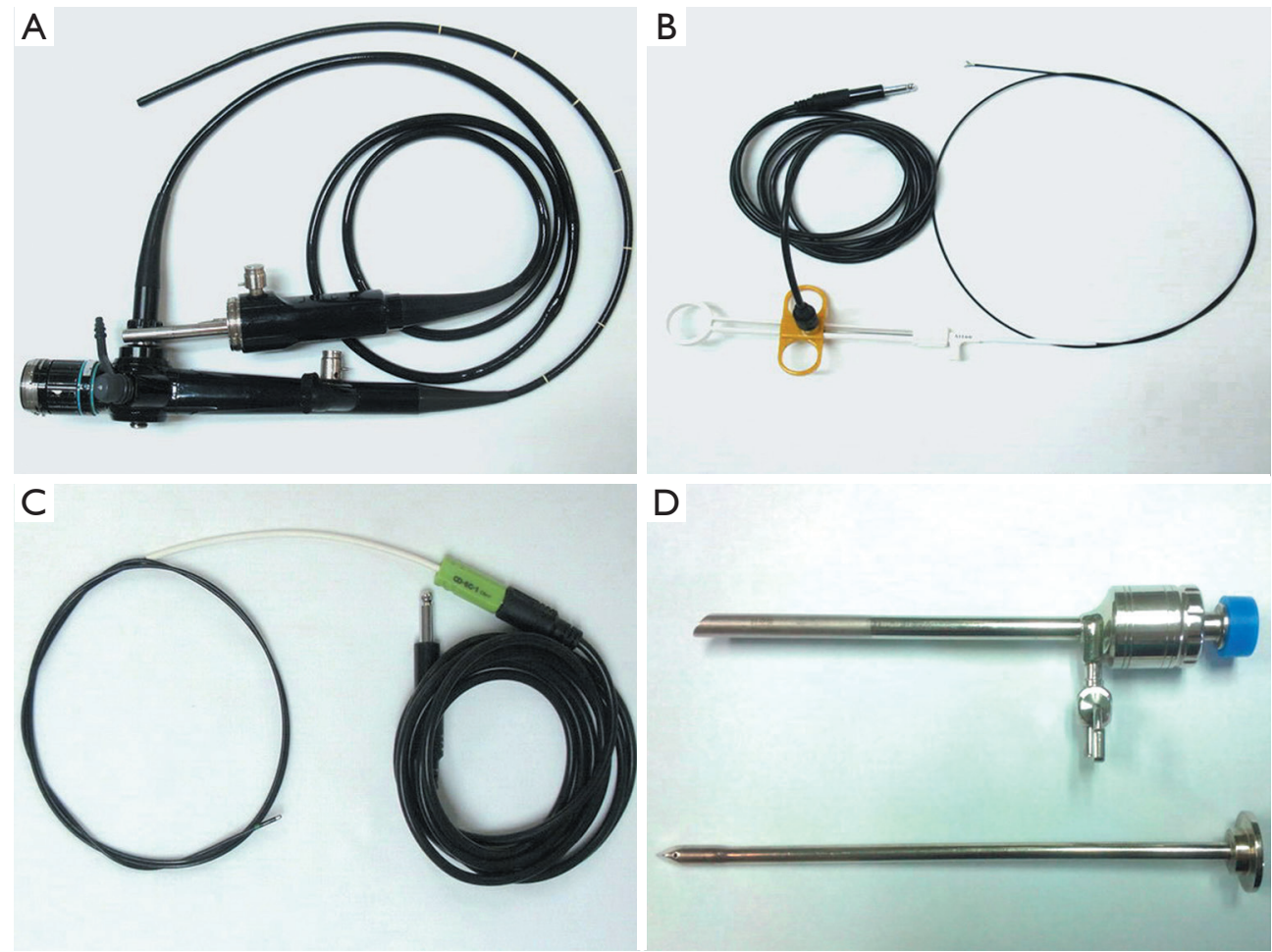

Figure 1 Equipment used to perform the transareolar single-port endoscopic thoracic sympathectomy (ETS). (A) A flexible endoscope with an instrumental channel that enables the passage of endoscopic apparatus into the thoracic cavity; (B) hot biopsy forceps applied to grasp and ablate the sympathetic chain; (C) the endoscopic electrotome employed to interrupt the tissue adjacent to the sympathetic chain; (D) a long trocar used as a guide for the flexible endoscope and to establish pneumothorax by insufflating the thoracic cavity with carbon dioxide.

$\leq 50$ years; male patients with severe PPH that substantially affected their daily life; no history of thoracic surgery and/ or severe chest wall deformity; and no contraindication to an anesthetic procedure with single-lumen endotracheal intubation. The exclusion criteria were as follows: plantar and/or axillary hyperhidrosis without palmar hyperhidrosis; any lung, pleural, or heart disease that potentially increased the surgical risks; secondary hyperhidrosis due to conditions such as hyperthyroidism, acute and chronic infections, malignancy, and immunologic disorders.

After the study procedure and objective were comprehensively explained, all patients provided written informed consent at least 1 day before the surgery. Patients were randomly allocated to group A or B via the distribution of sequentially numbered sealed envelopes containing the procedural information.

We assumed $\delta$ as $0.7, \sigma$ as $0.7(18), \alpha$ as $0.05, \beta$ as 0.10 , $t_{\frac{0.05}{2}}=1.645, \frac{t_{0.1}=1.282}{2}$, and $\mathrm{n}=2 \sigma^{2} \times \frac{f(\alpha, \beta)}{\left(\mu^{1}-\mu^{2}\right)^{2}}=42$. Assuming a dropout rate of $10 \%$, the minimum sample size required was 92. During the recruitment period from January 2019 to the end of September 2019, a total of 124 male patients were randomized, of which 62 patients received transareolar single-port ETS using a flexible endoscope (group A) and 62 patients received transaxillary single-port ETS using a traditional $5 \mathrm{~mm}$ thoracoscope (group B). Six patients were excluded from the analysis: surgical treatment was not performed in four patients because of the intraoperative discovery of extensive pleural adhesion (two patients in group A and two in group B), while two patients in group A declined to participate due to concerns about the risks associated with the new procedure. Therefore, the total number of included patients was 118 (58 cases in group A and 60 cases in group B).

\section{Surgical procedure}

One-stage bilateral sympathectomy was performed under general anesthesia with a single-lumen endotracheal tube for all patients. The patient was placed on the operating 


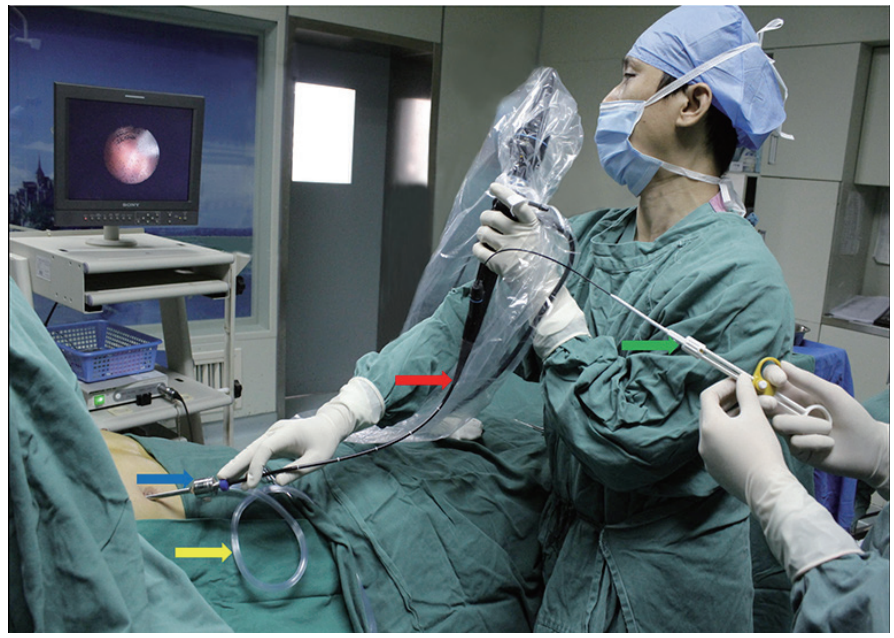

Figure 2 Photograph of a surgeon performing transareolar endoscopic thoracic sympathectomy (ETS). The coloured arrows indicate the following: blue = $20 \mathrm{~cm}$ long trocar; yellow = pipe used to insert carbon dioxide; red = flexible endoscope; green = hot biopsy forceps.
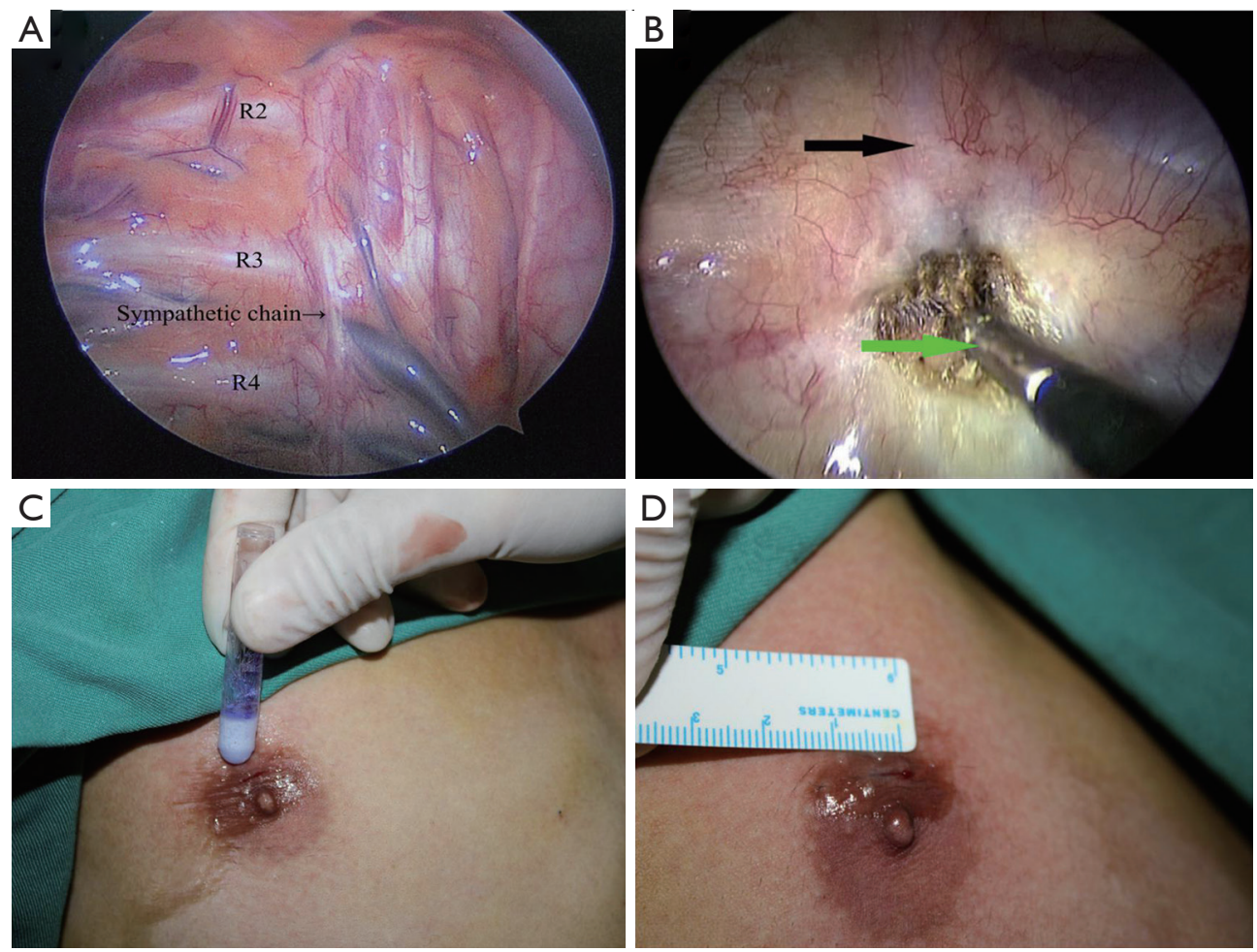

Figure 3 Intraoperative photographs of transareolar endoscopic thoracic sympathectomy (ETS) with a flexible endoscope. (A) Endoscopic view of the right thoracic cavity; (B) the sympathetic chain around rib 4 (black arrow) is grasped and ablated by the hot biopsy forceps (green arrow); (C) the transareolar incision is closed with Dermabond skin adhesive; (D) the closed $5 \mathrm{~mm}$ skin incision is hidden in the areola.

table in a semi-sitting position with both arms in abduction, exposing the areolae or axillae for sequential bilateral procedures and eliminating the need for repositioning. A palmar temperature probe was taped in place on the thenar eminence. The palmar temperature was kept below $30{ }^{\circ} \mathrm{C}$ before the operation by immersing the hand in water at $4^{\circ} \mathrm{C}$. 

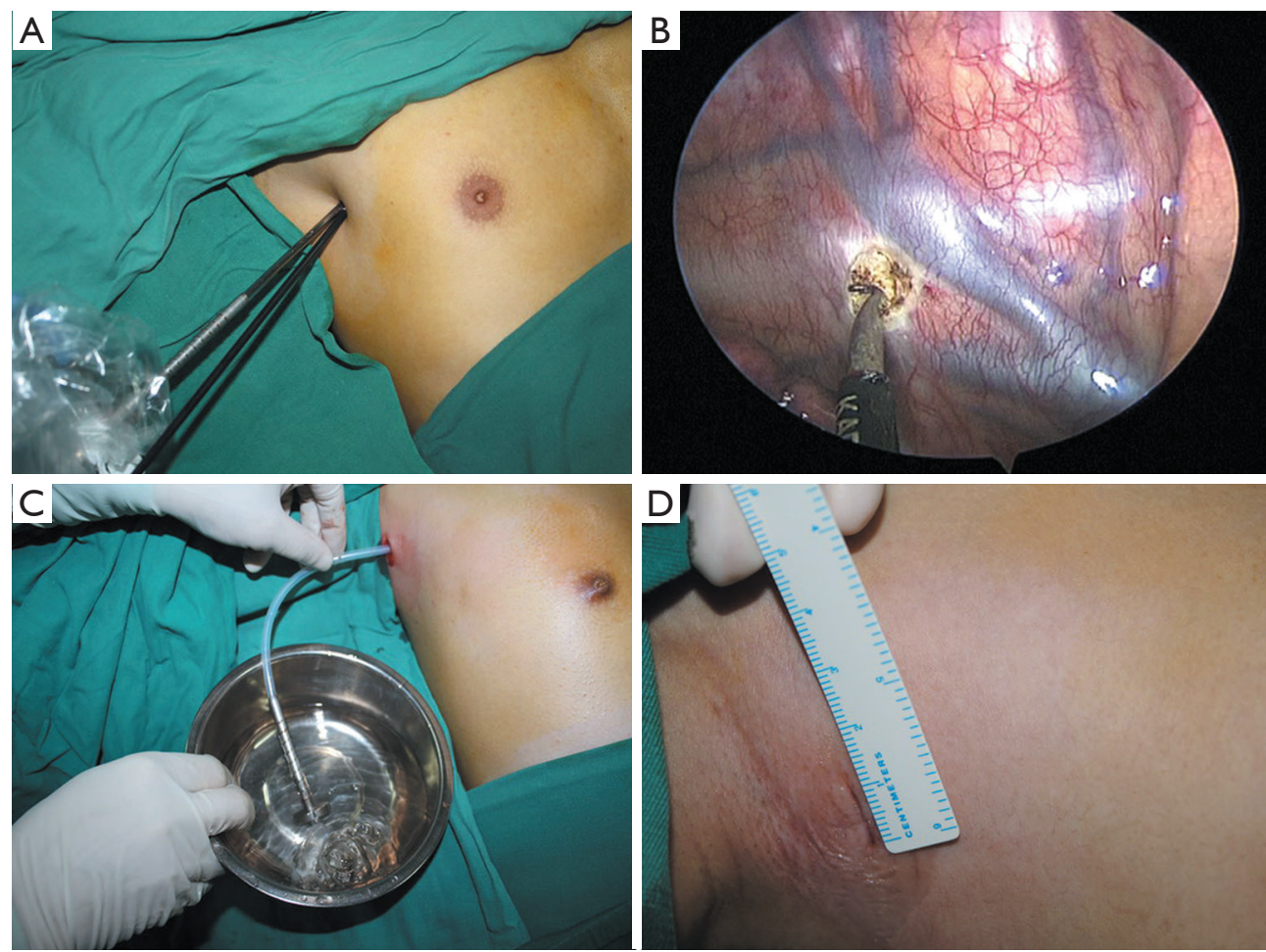

Figure 4 Intraoperative photographs of transaxillary endoscopic thoracic sympathectomy (ETS) with a $5 \mathrm{~mm}$ thoracoscope. (A) A $5 \mathrm{~mm}$ thoracoscope and cautery hook are introduced into the thoracic cavity through the same transaxillary port after the trocar is removed from the incision; (B) the sympathetic chain around rib 4 is ablated by the cautery hook; (C) drainage of the retained air before the incision closure; (D) the length of the transaxillary incision is $11 \mathrm{~mm}$.

The baseline palmar temperature was recorded before the skin incision.

For group A, a single $5 \mathrm{~mm}$ incision was made in the fourth intercostal space on the edge of the areola. A long trocar $(20 \mathrm{~cm}$ length, $4.6 \mathrm{~mm}$ internal diameter, $0.4 \mathrm{~mm}$ wall thickness) was inserted into the thoracic cavity to guide the flexible endoscope (BF-MP60: $4.4 \mathrm{~mm}$ outer diameter, $2.0 \mathrm{~mm}$ inner diameter of the instrumental channel; Olympus Medical Systems, Tokyo, Japan). The flexible endoscope was sterilized by STERRAO NX lowtemperature plasma sterilization system (Johnson \& Johnson Company, USA). The trocar was used to insufflate the thoracic cavity with carbon dioxide at $8 \mathrm{mmHg}$ to establish pneumothorax (Figure 2). As the first rib cannot be seen in the thoracic cavity in most cases, the uppermost visualized rib was considered the second rib, and the subsequent ribs were considered the third and fourth ribs. After identification of the sympathetic chain, local nerve block was performed with $5 \mathrm{~mL} 2 \%$ lidocaine via an endoscopic syringe. Subsequently, hot biopsy forceps (Alton
Medical Equipment, Shanghai, China) were used to grasp and ablate the sympathetic chain crossing the fourth rib (R4) (Figure 3). Approximately $2 \mathrm{~cm}$ of tissue adjacent to $\mathrm{R} 4$ was interrupted laterally with an endoscopic electrotome (PSD20; Olympus Medical Systems, Tokyo, Japan) to include any accessory nerve fibers (the nerve of Kuntz). The intended depth of ablation was to the periosteum of the rib. An increase in palmar temperature of $1.5^{\circ} \mathrm{C}$ indicated adequate sympathectomy. The above-mentioned measures were taken to ensure the complete ablation of the sympathetic chain. Endoscopic devices were removed after the sympathectomy. Mild vacuum suction was then applied to re-expand the lung. The anesthesiologist ventilated the patient manually, and pneumothorax was prevented by exerting continuous positive pressure for a few seconds (Video 1).

Group B received a traditional single $11 \mathrm{~mm}$ transaxillary incision in the third intercostal space on the anterior axillary line. After temporarily disconnecting the tracheal tube, a $6 \mathrm{~mm}$ trocar with a blunt obturator was inserted into the thoracic cavity. The obturator of the trocar was 
Table 1 Follow-up questionnaire

Responses to questions

Results after operation

Hands: worse/unchanged/partial remission/completely dry

Axillae: worse/unchanged/partial remission/completely dry

Feet: worse/unchanged/partial remission/completely dry

Compensatory hyperhidrosis

No/yes

Location: back, abdomen, lower extremities, thorax, other part of body

Level: none/mild/moderate/severe a

Residual pain

No/yes

Cosmetic results

Verbal response scale (VRS): 1 = dissatisfied $/ 2=$ acceptable $/ 3=$ satisfied $/ 4=$ perfect

Satisfaction score

Analogue visual scale (AVS): very satisfied [9-10]/satisfied [6-8]/dissatisfied [3-5]/very dissatisfied [0-2]

${ }^{a}$, the degree of postoperative compensatory sweating was classified as mild (undergarments remained dry despite heavy sweating), moderate (undergarments were sometimes soaked with excessive sweat but were tolerable), and severe (undergarments were sometimes soaked with excessive sweat and became intolerable, requiring changes more than twice a day).

pulled out to create open pneumothorax. After 10 seconds of ventilatory suspension, the lung was deflated from the vertex of the thoracic cavity under gravity. A $5 \mathrm{~mm} 30^{\circ}$ thoracoscope (Karl Storz, Tuttlingen, Germany) was then incorporated into the thoracic cavity. After the trocar was removed, a $5 \mathrm{~mm}$ cautery hook was inserted into the thoracic cavity through the same port. The sympathetic chain was identified and ablated by the cautery hook. Approximately $2 \mathrm{~cm}$ of tissue adjacent to $\mathrm{R} 4$ was routinely disrupted laterally. The increase in palmar temperature was measured by a palmar temperature probe to confirm adequate sympathectomy. Once the sympathectomy was completed, the cautery hook was removed, and the trocar was inserted along the thoracoscope into the thoracic cavity. The thoracoscope was then removed, and the trocar was left in position as a vent for retained air. A $12 \mathrm{~F}$ chest tube was inserted through the trocar (Figure 4). The chest tube was aspirated while the anesthesiologist ventilated the patient manually to exert continuous positive pressure for a few seconds. The chest tube was subsequently removed before the drainage.

At the end of surgery, the incision was pressed tightly for a few seconds to ensure that there was no active bleeding. The incision was closed with Dermabond skin adhesive (Ethicon, West Somerville, NJ, USA) without the need for any sutures or dressing. The entire procedure was repeated on the opposite side without changing the position of the patient or the operational setting.

\section{Follow-up and data collection}

Patients were followed up for 6-14 months by hospital visit, telephone, or e-mail. The average follow-up duration was $9.3 \pm 2.1$ months. Patients were required to complete a detailed questionnaire at the end of the follow-up (Table 1) (19). The data collected included resolution of symptoms, compensatory hyperhidrosis, cosmetic score, satisfaction score, residual pain score, and recurrence.

\section{Statistical analysis}

Statistical analysis was performed using SPSS version 18.0 (SPSS, Chicago). For quantitative variables that conformed to normal distribution, the mean \pm standard deviation was calculated to indicate the variance, and $t$ test was used to compare the differences between the two groups; otherwise, the median and quartile was calculated, and Wilcoxon rank sum test was used. Qualitative variables were expressed as a percentage and Pearson's chi-squared test or Fisher's exact probability method was adopted. The patient characteristics were compared between the two groups, and two-sided values of $\mathrm{P}<0.05$ were considered statistically significant.

\section{Results}

\section{Overall results}

A total of 118 bilateral ETS procedures were successfully performed in our hospital. Age, history of non-surgical treatments, family history, and distribution of sweating were similar in both groups (Table 2). No conversion to open technique was necessary, and there was no operative mortality. The palms of all patients became dry and warm after the sympathectomy. Hospital stays were short, with 114 patients $(96.6 \%)$ discharged on the first postoperative 
Table 2 Patient characteristics

\begin{tabular}{|c|c|c|c|}
\hline Characteristics & Group A $(n=58)$ & Group B $(n=60)$ & $P$ value \\
\hline History of non-surgical treatments, n (\%) & $31(53.4)$ & $35(58.3)$ & $>0.05$ \\
\hline Positive family history, $\mathrm{n}(\%)$ & $15(25.9)$ & $17(28.3)$ & $>0.05$ \\
\hline Distribution of hyperhidrosis, $\mathrm{n}(\%)$ & & & $>0.05$ \\
\hline Plus plantar hyperhidrosis & $15(25.9)$ & $17(28.3)$ & \\
\hline Plus axillary hyperhidrosis & $13(22.4)$ & $11(18.3)$ & \\
\hline Plus plantar and axillary hyperhidrosis & $22(37.9)$ & $25(41.7)$ & \\
\hline
\end{tabular}

Group A: males with severe primary palmar hyperhidrosis who underwent transareolar endoscopic thoracic sympathectomy using a flexible endoscope; group B: males with severe primary palmar hyperhidrosis who underwent transaxillary endoscopic thoracic sympathectomy using a 5-mm thoracoscope.

Table 3 Operative outcomes

\begin{tabular}{|c|c|c|c|}
\hline Demographics & Group A $(n=58)$ & Group B $(n=60)$ & $P$ value \\
\hline Postoperative pain score ${ }^{a}$ & $1.3 \pm 0.5$ & $3.4 \pm 0.6$ & $<0.004$ \\
\hline Analgesia after operation, $\mathrm{n}(\%)$ & $0(0.0)$ & $6(10.0)$ & $<0.004$ \\
\hline Mean operating time, $\min ^{\mathrm{b}}$ & $27.8 \pm 2.1$ & $26.9 \pm 3.6$ & $>0.004$ \\
\hline Intraoperative bleeding, n (\%) & $0(0.0)$ & $2(3.3)$ & $>0.004$ \\
\hline Postoperative pneumothorax, n (\%) & $3(5.2)$ & $4(6.7)$ & $>0.004$ \\
\hline Chest drainage for pneumothorax, $\mathrm{n}(\%)$ & $1(1.7)$ & $1(1.7)$ & $>0.004$ \\
\hline Transient postoperative sweating, n (\%) & $4(6.9)$ & $3(5.0)$ & $>0.004$ \\
\hline
\end{tabular}

${ }^{a}$, rated from 0 (no pain) to 10 (worst pain imaginable). ${ }^{b}$, recorded from the time of skin incision to the application of the dressing over the incision. This excluded anaesthesia induction and resuscitation time. Group A: males with severe primary palmar hyperhidrosis who underwent transareolar endoscopic thoracic sympathectomy using a flexible endoscope; group B: males with severe primary palmar hyperhidrosis who underwent transaxillary endoscopic thoracic sympathectomy using a 5-mm thoracoscope.

day and the rest discharged on the second postoperative day.

\section{Operative outcomes}

Operative outcomes of both groups are shown in Table 3. The median incision length in group A [5.1 (5.0-5.2)] was significantly shorter than that in group B [10.9 (10.8-11.9)] $(\mathrm{P}<0.001)$, and the median postoperative pain score was significantly higher in group B [3 (3.0-4.0)] than in group A [1 $(1.0-2.0)](\mathrm{P}<0.001)$. Postoperative analgesia was required by 6 patients $(10.0 \%)$ in group $B$ compared with no patients in group $\mathrm{A}(\mathrm{P}<0.001)$. There were no differences between the two groups in mean operative time, mean palmar temperature increase, and transient postoperative sweating.

\section{Postoperative complications}

Postoperative complications were minor. Two patients in group B had intraoperative bleeding secondary to paravertebral vein injury. The bleeding required the insertion of a second trocar and the application of an endoclip, without any need for open surgery. Postoperative pneumothorax was found on the chest $\mathrm{X}$-rays of seven patients; this was resolved after chest drainage for 1 day in 
Table 4 Postoperative follow-up outcomes

\begin{tabular}{lccc}
\hline Demographics & Group A $(\mathrm{n}=58)$ & Group B $(\mathrm{n}=60)$ & \\
\hline Resolution of symptoms, $\mathrm{n}(\%)$ & $58(100.0)$ & $60(100.0)$ & $>0.004$ \\
Palmar hyperhidrosis & $24(64.9)$ & $26(61.9)$ & $>0.004$ \\
Plantar hyperhidrosis & $20(57.1)$ & $22(61.1)$ & $>0.004$ \\
Axillary hyperhidrosis & $21(36.2)$ & $20(33.3)$ & $>0.004$ \\
Compensatory hyperhidrosis, $\mathrm{n}(\%)$ & $3.8 \pm 0.6$ & $3.2 \pm 0.7$ & $>0.05$ \\
Mean cosmetic score & $9.2 \pm 0.7$ & $9.0 \pm 0.6$ & $>0.004$ \\
Mean satisfaction score & &
\end{tabular}

Group A: males with severe primary palmar hyperhidrosis who underwent transareolar endoscopic thoracic sympathectomy using a flexible endoscope; group B: males with severe primary palmar hyperhidrosis who underwent transaxillary endoscopic thoracic sympathectomy using a 5-mm thoracoscope.

two patients (lung compression $>30 \%$ ), while the other five patients did not require further intervention. There was no occurrence of Horner's syndrome or wound infection in any patient.

Follow-up began 6 months after the last operation with $100 \%$ completion rate, and the median followup was 9 months. The follow-up was finished when the questionnaires were received and when the postoperative condition of each patient was fully understood. The followup outcomes are shown in Table 4. The median cosmetic score was significantly higher in group A [4.0 (3.0-4.0)] than group B [3.0 (3.0-3.0)] $(\mathrm{P}<0.001)$. There were no significant differences between the two groups regarding resolution of symptoms, compensatory hyperhidrosis, or satisfaction score. No patient in either group reported residual pain or recurrence of symptoms.

\section{Discussion}

In the management of PPH, non-surgical treatments such as botulinum toxin, systemic anticholinergic agents, local antiperspirants, and iontophoresis only transiently alleviate symptoms and have a high rate of recurrence (20-22). At present, the most popular and effective treatment for $\mathrm{PPH}$ is ETS. The ablation devices commonly used in ETS are a $5 \mathrm{~mm}$ thoracoscope, a $5 \mathrm{~mm}$ cautery hook, and a $6 \mathrm{~mm}$ trocar. Although traditional ETS provides persistent effectiveness, a high degree of safety, and cosmetic benefits (23), the procedure still results in permanent cosmetic defects, postoperative wound-related pain, numbness or paresthesia, and visible scars on the chest wall.

As PPH commonly affects young people, the cosmetic outcome of ETS is an important issue. Numerous attempts to improve cosmetic outcomes have promoted the development of minimally invasive surgical procedures such as transaxillary single-port ETS. Although the transaxillary single-port approach has achieved good results (24-26), there are still some shortcomings. First, the size of the incision created in transaxillary single-port ETS is actually equal to the size of the incision used in traditional two-port ETS [10-15 cm according to the latest reports (24-26)] that allows two surgical instruments to operate in the same port, thereby causing substantial postoperative pain. In addition, it is often difficult to insert the cautery hook along the thoracoscope into the thoracic cavity through the same port, and so the incision sometimes has to be enlarged. Finally, in transaxillary single-port ETS, the smoke generated from the nerve ablation cannot be easily removed from the thoracic cavity, as the chest cavity is isolated from the atmosphere. The smoke greatly affects the surgical view and increases the surgical risk.

To overcome these shortcomings of traditional ETS, we employed a flexible endoscope to perform transareolar single-port ETS, and achieved results that were consistent with those previously reported for ETS $(27,28)$. The effectiveness of $\mathrm{PPH}$ treatment was $100 \%$, and no patient required open surgery. Horner's syndrome occurs due to direct or indirect lesions of the stellate ganglion, and the incidence of Horner's syndrome after thoracoscopic sympathectomy varies from $0.5-17 \%$ (29). In the present study, no patient developed Horner's syndrome, possibly because the level of R4 sympathetic transection was distant from the stellate ganglion. Recurrence rates after thoracoscopic sympathectomy for palmar anhidrosis 

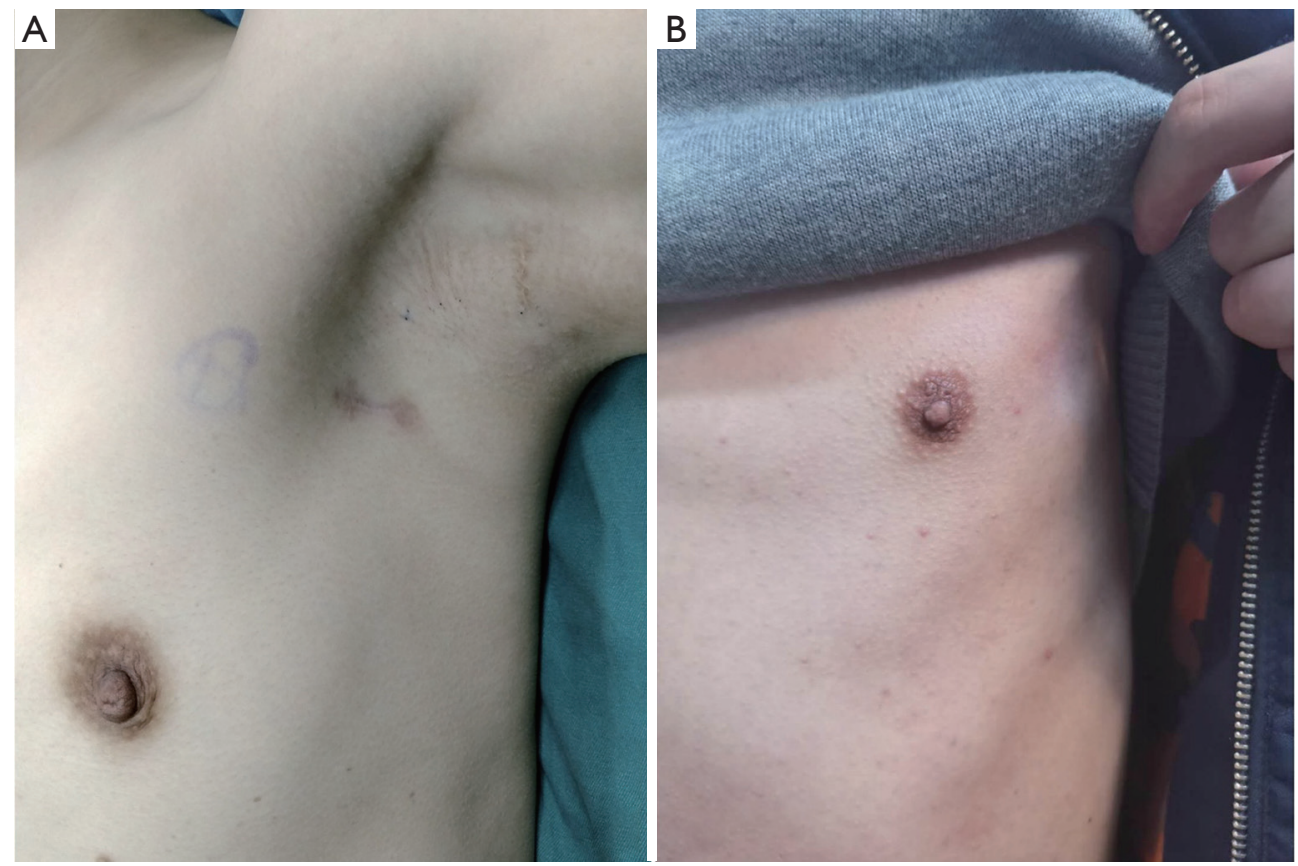

Figure 5 Postoperative photographs showing the cosmetic outcomes after transareolar endoscopic thoracic sympathectomy (ETS) (group A) and after transaxillary ETS (group B). (A) Photograph of a patient from group A showing the absence of a surgical scar on the chest wall at 8 months postoperatively; (B) photograph of a patient from group B showing an obvious surgical scar in the axilla at 10 months postoperatively.

reportedly vary considerably from $1 \%$ to $27 \%$ (30), mostly due to incomplete thoracic sympathectomy, anatomic variability of the sympathetic chain, and nerve regeneration. However, there was no recurrence during follow-up in the present study, probably because the sympathetic ganglion and the nerve of Kuntz were completely ablated. The most common early postoperative complication in the present study was pneumothorax; however, pneumothorax can be prevented by continuous exertion of positive pressure for a few seconds in coordination with the application of mild suction before the closure of the skin incision. Compensatory hyperhidrosis is the most undesirable side effect of ETS, with an incidence of 3-98\% (8). Such wide variation in the incidence of compensatory hyperhidrosis may be attributed to different levels of nerve ablation, emotional stress, or interstudy variation in the definition of compensatory hyperhidrosis. In the present study, compensatory hyperhidrosis occurred in $36.2 \%$ of patients in group A. Most of these cases were mild to moderate, and the most commonly affected areas were the back, thorax, abdomen, and lower extremities. However, the symptoms were not severe enough to interfere with the patients' lifestyles, and further treatment was not required. Although the pathogenesis of compensatory hyperhidrosis remains unknown, it may be associated with a temperatureregulating compensatory mechanism in accordance with the extent of sympathectomy (14).

Follow-up results revealed a better cosmetic outcome in group A than in group B (Figure 5). However, the mean satisfaction score did not significantly differ between groups A and B. We consider that the level of satisfaction depends mainly on whether the symptoms are resolved. As the resolution rate of $\mathrm{PPH}$ was $100 \%$ and there was no recurrence in either group, it is reasonable that the two groups achieved similar satisfaction scores.

Compared with traditional transaxillary single-port ETS, this novel transareolar single-port ETS procedure is less invasive and provides several advantages. First, the flexible endoscope has the advantage of combining two ports (one for the illuminating system and the other for introducing endoscopic instruments to ablate the sympathetic chain) into one. The short $5 \mathrm{~mm}$ single incision used for transareolar single-port ETS in our study was associated with less pain and better cosmetic results 
than transaxillary single-port ETS. Second, in transareolar single-port ETS, the instrumental channel can be used for additional apparatus including the endoscopic syringe, the endoscopic hot biopsy forceps, an electrotome, and the vacuum suction, eliminating the need for extra ports. It thus avoids the difficulty of inserting the cautery hook and the inconvenience caused by the simultaneous use of two instruments through a single incision in conventional singleport ETS. Third, the novel transareolar single-port ETS obtains a much better surgical view (31) than traditional ETS by insufflating the thoracic cavity with carbon dioxide and using a mild vacuum suction to remove the smoke generated by the nerve ablation. Finally, transareolar singleport ETS achieved excellent cosmetic results by hiding the incisions in the areolae, with no visible surgical scars on the chest wall at several months postoperatively. However, transaxillary single-port ETS avoids the risk of injury to the mammary glands and is more suitable for female patients.

Although the novel transareolar ETS procedure described in the present study has overcome several limitations of traditional methods, there were some issues. The flexible endoscope was so thin and soft that there was a lack of force transmission when the endoscope entered the thoracic cavity, thereby requiring a long trocar to guide the operative direction. Furthermore, the sample size was small, and the follow-up time was relatively short. Studies with more patients and a longer follow-up time are needed to evaluate the long-term outcomes of transareolar single-port ETS.

\section{Conclusions}

The present study demonstrates that transareolar singleport ETS is effective and safe as a standard therapy in males. Compared with conventional transaxillary singleport ETS using a $5 \mathrm{~mm}$ thoracoscope, this novel technique provided excellent cosmetic results and less pain due to a smaller incision, and is suitable for use in male patients as a routine clinical treatment for $\mathrm{PPH}$.

\section{Acknowledgments}

We thank Kelly Zammit, BVSc, from Liwen Bianji, Edanz Editing China (www.liwenbianji.cn/ac), for editing the English text of a draft of this manuscript.

Funding: This study was supported by the Natural Science Foundation of China (Grant 81701241), Scientific and Joint Funds for the innovation of science and Technology, Fujian province (Grant 2019Y9119), and was registered in

\section{ChiCTR (ChiCTR1900020762).}

\section{Footnote}

Reporting Checklist: The authors have completed the CONSORT reporting checklist. Available at http://dx.doi. org/10.21037/atm-20-7399

Data Sharing Statement: Available at http://dx.doi. org/10.21037/atm-20-7399

Conflicts of Interest: All authors have completed the ICMJE uniform disclosure form (available at http://dx.doi. org/10.21037/atm-20-7399). The authors have no conflicts of interest to declare.

Ethical Statement: The authors are accountable for all aspects of the work in ensuring that questions related to the accuracy or integrity of any part of the work are appropriately investigated and resolved. All procedures performed in studies involving human participants were in accordance with the ethical standards of the institutional and/or national research committee and with the study conformed to the provisions of the Declaration of Helsinki (as revised in 2013). This study was approved by the institutional review board and ethics committee of the First Affiliated Hospital of Fujian Medical University (approval no. 2015-17). Informed consent was obtained before surgery.

Open Access Statement: This is an Open Access article distributed in accordance with the Creative Commons Attribution-NonCommercial-NoDerivs 4.0 International License (CC BY-NC-ND 4.0), which permits the noncommercial replication and distribution of the article with the strict proviso that no changes or edits are made and the original work is properly cited (including links to both the formal publication through the relevant DOI and the license). See: https://creativecommons.org/licenses/by-nc-nd/4.0/.

\section{References}

1. Sato K, Kang WH, Saga K, et al. Biology of sweat glands and their disorders. II. Disorders of sweat gland function. J Am Acad Dermatol 1989;20:713-26.

2. Hornberger J, Grimes K, Naumann M, et al. Recognition, diagnosis, and treatment of primary focal hyperhidrosis. $\mathrm{J}$ Am Acad Dermatol 2004;51:274-86. 
3. Lai YT, Yang LH, Chio CC, et al Complications in patients with palmar hyperhidrosis treated with transthoracic endoscopic sympathectomy. Neurosurgery 1997;41:110-3; discussion 113-5.

4. Lai FC, Tu YR, Li YP, et al. Nation wide epidemiological survey of primary palmar hyperhidrosis in the People's Republic of China. Clin Auton Res 2015;25:105-8.

5. Strutton DR, Kowalski JW, Glaser DA, et al. US prevalence of hyperhidrosis and impact on individuals with axillary hyperhidrosis: results from a national survey. J Am Acad Dermatol 2004;51:241-8.

6. Westphal FL, de Carvalho MA, Lima LC, et al. Prevalence of hyperhidrosis among medical students. Rev Col Bras Cir 2011;38:392-7.

7. Chen J, Lin M, Chen X, et al. A novel locus for primary focal hyperhidrosis mapped on chromosome 2q31.1. Br J Dermatol 2015;172:1150-3.

8. Streker M, Kerscher M. Antiperspirants for the therapy of focal hyperhidrosis. Hautarzt 2012; 63, 452-5.

9. Campanati A,Giuliodori K,Giuliano A, et al. Treatment of palmar hyperhidrosis with botulinum toxin type A: results of a pilot study based on a novel injective approach. Arch Dermatol Res 2013;305:691-7.

10. Guo JG, Fei Y, Huang B, Yao M. CT-guided thoracic sympathetic blockade for palmar hyperhidrosis: Immediate results and postoperative quality of life. J Clin Neurosci 2016;34:89-93.

11. Hale DR, MacKenzie AI, Kavanagh GM. Our experience of glycopyrrolate $2 \%$ cream for axillary hyperhidrosis. Br J Dermatol 2014;170:1373.

12. Campanati A, Sandroni L, Gesuita R, et al. Treatment of focal idiopathic hyperhidrosis with Botulinum Toxin Type A: clinical predictive factors of relapse-free survival.J Eur Acad Dermatol Venereol 2011, 25: 917-21.

13. Lakraj AA, Moghimi N, Jabbari B. Hyperhidrosis: anatomy, pathophysiology and treatment with emphasis on the role of botulinum toxins. Toxins (Basel) 2013;5:821-40.

14. Cerfolio RJ, De Campos JR, Bryant AS, et al. The Society of Thoracic Surgeons expert consensus for the surgical treatment of hyperhidrosis. Ann Thorac Surg 2011;91:1642-8.

15. Chen JF, Du Q,Lin M, et al. Transareolar SinglePort Needlescopic Thoracic Sympathectomy Under Intravenous Anesthesia Without Intubation: A Randomized Controlled Trial. J Laparoendosc Adv Surg Tech A 2016;26:958-64.

16. Chen JF, Lin JB, Tu YR, et al. Nonintubated transareolar single-port thoracic sympathicotomy with a needle scope in a series of 85 male patients.Surg Endosc 2016;30:3447-53.

17. Assouad J, Fénane H, Masmoudi H, et al. (Flexible endoscope in thoracic surgery: CITES or cVATS?). Rev Pneumol Clin 2013;69:294-7.

18. Shan YZ, Zhou LM, Yu ZF, et al. Comparison between transareola singlesite endoscopic thyroidectomy and minimally invasive video-assisted thyroidectomy. J Int Med Res 2012;40:2213-9.

19. Chen J, Lin J, Tu Y, et al. Nonintubated Transareolar Endoscopic Thoracic Sympathectomy with a Flexible Endoscope: Experience of 58 Cases. Ann Thorac Cardiovasc Surg 2016;22:12-9.

20. Schnider P, Moraru E, Kittler H, et al. Treatment of focal hyperhidrosis with botulinum toxin type A: long-term follow-up in 61 patients. Br J Dermatol 2001;145:289-93.

21. Hale DR, MacKenzie AI, Kavanagh GM. Our experience of glycopyrrolate $2 \%$ cream for axillary hyperhidrosis. $\mathrm{Br} \mathrm{J}$ Dermatol 2014;170:1373.

22. Lakraj AA, Moghimi N, Jabbari B. Hyperhidrosis: anatomy, pathophysiology and treatment with emphasis on the role of botulinum toxins. Toxins (Basel) 2013;5:821-40.

23. Li X, Tu YR, Lin M, et al. Endoscopic thoracic sympathectomy for palmar hyperhidrosis: a randomized control trial comparing T3 and T2-4 ablation. Ann Thorac Surg 2008;85:1747-51.

24. Chen YB, Ye W, Yang WT, et al. Uniportal versus biportal video-assisted thoracoscopic sympathectomy for palmar hyperhidrosis. Chin Med J (Engl) 2009;122:1525-8.

25. Bouma W, Klinkenberg TJ, Mariani MA. Bilateral single-port thoracoscopic sympathectomy with the VasoView device in the treatment of palmar and axillary hyperhidrosis. Interact Cardiovasc Thorac Surg 2011;12:106-9.

26. Atkinson JL, Fode-Thomas NC, Fealey RD, et al. Endoscopic transthoracic limited sympathotomy for palmar-plantar hyperhidrosis: outcomes and complications during a 10-year period. Mayo Clin Proc 2011;86:721-9.

27. Jeganathan R, Jordan S, Jones M, et al. Bilateral thoracoscopic sympathectomy: results and long-term follow-up. Interact Cardiovasc Thorac Surg 2008;7:67-70.

28. Liu Y, Yang J, Liu J, et al. Surgical treatment of primary palmar hyperhidrosis: a prospective randomized study comparing T3 and T4 sympathicotomy. Eur J Cardiothorac Surg 2009;35:398-402.

29. Singh B, Moodley J, Allopi L, et al. Horner syndrome after sympathectomy in the thoracoscopic era. Surg Laparosc Endosc Percutan Tech 2006;16:222-5.

30. Rodríguez PM, Freixinet JL, Hussein M, et al. Side 
Page 12 of 12

effects, complications and outcome of thoracoscopic sympathectomy for palmar and axillary hyperhidrosis in 406 patients. Eur J Cardiothorac Surg 2008;34:514-9.

31. Lin JB, Chen JF, Lai FC, et al. Transareolar pulmonary

\section{Lin et al. Transareolar single-port ETS vs. transaxillary ETS}

bullectomy for primary spontaneous pneumothorax. J

Thorac Cardiovasc Surg 2016;152:999-1005.

(English Language Editor: D. Fitzgerald)

Cite this article as: Lin JB, Kang MQ, Chen JF, Du Q, Li X, Lai FC, Tu YR. Transareolar single-port endoscopic thoracic sympathectomy with a flexible endoscope for primary palmar hyperhidrosis: a prospective randomized controlled trial. Ann Transl Med 2020;8(24):1659. doi: 10.21037/atm-20-7399 